\title{
The Effects of Sport Education and Fine Arts Education on Social Appearance Anxiety
}

\author{
Egemen Ermiş ${ }^{1}$, Gülten Imamoğlu ${ }^{2}$ \\ ${ }^{1}$ Ondokuz Mayıs University, Yaşar Doğu Faculty of Sport Sciences, Samsun, Turkey \\ ${ }^{2}$ Ondokuz Mayıs University, Faculty of Fine Arts, Samsun, Turkey \\ Correspondence: Egemen Ermiş, Ondokuz Mayıs University, Yaşar Doğu Faculty of Sport Sciences, Samsun, Turkey.
}

Received: March 18, 2019

doi:10.11114/jets.v7i6.4147

Accepted: April 11, 2019

Online Published: April 22, 2019

URL: https://doi.org/10.11114/jets.v7i6.4147

\begin{abstract}
The purpose of this study is to compare the social appearance anxiety levels of university students studying in different fields. Social appearance anxiety scales which were filled in by 481 students were assessed in the study. T-test and one way ANOVA were used for statistical analysis, while LSD tests were used to find out differences.

Social appearance anxiety scale scores were found to be higher in male students when compared with female students. No statistically significant difference was found between social appearance anxiety scale scores in terms of genders $(\mathrm{p}>0.05)$. In terms of field of education, social appearance anxiety scale scores of students receiving sport education were found to be lower than the scores of students receiving art and music education and the highest social appearance anxiety scale scores were found in students in the department of educational sciences. Statistically significant difference was found between social appearance anxiety scale scores in terms of field of education $(\mathrm{p}<0.001)$.

As a conclusion, it was found that sport education caused a higher decrease in social appearance anxiety when compared with fine arts education, while fine arts education caused a decrease in social appearance anxiety when compared with students who received neither sport nor fine arts education. In terms of social appearance contribution, it is thought that art and music education have similar effects to those of sport. Giving sport education to students who are not receiving sport education or making them do sport and giving those interested in sport a chance to be interested in art can be a factor in decreasing social appearance anxiety.
\end{abstract}

Keywords: social appearance anxiety, sport, art and music

\section{Introduction}

Social appearance anxiety is about the appearance of an individual; however, it includes an individual's thoughts about his/her body rather than his/her physical appearance. Social appearance anxiety, which should be discussed within the context of social anxiety, can also be thought of as an individual's assessment of his/her body (Yüceant, 2013). Social appearance anxiety is what individuals feel about the assessment of their physical build by others. Individuals have their own perceptions about their physical build. Some individuals feel anxious about how their appearance is perceived by others. They take action to create positive impression on others and when they fail in doing this, they can feel disappointed (Mülazımoğlu Ballı et al., 2014). According to Hart et al. (2008), the concept of social appearance anxiety is a more comprehensive concept that includes an individual's skin color and face shape beyond the individual's general physical appearance such as height, weight and muscle build. Human beings are assessed according to their beauty and from childhood to adulthood, positive values are attributed to beautiful, while negative values are attributed to ugly. People develop feelings and attitudes about their bodies according to ideal measures presented to them. Not having the desired measures can cause negativity in individuals' self-assessment (Yamak et al.,2016).

While individuals who have positive physical assessment of themselves are safer in their interpersonal relationships and more successful in their professions, those who do not like themselves and who think that they have many defects continually have uneasy, unsafe and worthless feelings in different periods of their lives (Ergür 1996, Demirer, 2005). Social appearance anxiety has negative impacts on individuals' social, academic and professional aspects (Dindar and Akbulut,2015). In university environment, students have a tendency to create positive impressions on other people with their physical appearance. Thus, it is an expected situation for university students who are not pleased with their 
physical build to experience some psychological problems (Kılıç, 2015).

It is thought that participating in physical activity increases self understanding and self confidence in individuals, develops social communication skills, increases cooperation and gentlemanship spirit and helps to decrease mental fatigue and tension (Gür and Küçükoğlu,1992). Physical activity gives people a feeling of personal identity, social identity and group membership. In addition, since physical activity is a phenomenon that does not discriminate between race, gender, age and culture, it goes beyond tension and conflict and enables communication between people and societies. Physical activity is a tool that has the power to make individuals members of a family, city or nation (Yıldiran and Yetim, 1996). Does social appearance anxiety differ according to variables of gender, faculty and year of study? It has also been researched whether social appearance anxiety differs according to variables of doing sport, being pleased with weight and height.

It is thought that social appearance anxiety can be decreased by receiving sport and fine arts education. For this purpose, the present study was planned on students receiving sport and fine arts education and students of educational sciences to test this hypothesis. The aim of this study is to find out the effects of sport and fine arts education on university students' social appearance anxiety.

\section{Method}

The present study was conducted on students of Ondokuz Mayis University who were between the ages of 18 and 24 . The students were studying in Yaşar Doğu Faculty of Sport Sciences, Faculty of Fine Arts department of Art and Faculty of Education departments of Music and Educational Sciences. A questionnaire form including personal information and social appearance anxiety scale was given to students. Of these forms, the forms of 481 students who filled in the questionnaire and the scale in full were assessed. Social Appearance Anxiety Scale was developed by Hart et al. (2008) to measure social appearance anxieties of individuals. It was adapted into Turkish by Doğan (2010). The scale includes 16 items. It is a 5-Likert type scale and the items are answered as (1) Not at all characteristic of me, (5) extremely characteristic of me. The first item of the scale is reversely coded. Social Appearance Anxiety Scale measures social appearance anxiety multi dimensionally and high scores taken from the scale mean high appearance anxiety. Cronbach Alpha internal consistency coefficient of the scale was found as 0.83 . In data analysis, descriptive statistics (frequency, percentage, arithmetic mean, standard deviation), t-test for independent groups, one way ANOVA for independent groups and LSD tests for finding out difference were used.

\section{Results}

Tables about the social appearance anxieties of the university students included in the study are given below.

Table 1 . Students' age, height and weight values and social appearance anxiety states

\begin{tabular}{|c|c|c|c|c|c|c|c|}
\hline & & $\mathrm{N}$ & Ave. & $\begin{array}{c}\text { St. } \\
\text { deviation }\end{array}$ & Min. & Max. & $\mathrm{t}$ \\
\hline \multirow[t]{2}{*}{ Age (Years) } & Male & 245 & 22.43 & 1.80 & 18 & 26 & 1.24 \\
\hline & Female & 236 & 22.19 & 2.21 & 17 & 33 & \\
\hline \multirow[t]{2}{*}{ Height $(\mathrm{cm})$} & Male & 245 & 177.56 & 8.74 & 160 & 191 & $5.72 * *$ \\
\hline & Female & 236 & 167.54 & 7.89 & 145 & 180 & \\
\hline Weight & Male & 245 & 76.14 & 15.20 & 57 & 105 & $-12.40 * *$ \\
\hline$(\mathrm{kg})$ & Female & 236 & 62.60 & 15.16 & 43 & 84 & \\
\hline Body Mass Index & Male & 245 & 24.64 & 2.70 & 17 & 34 & $-8.10 * *$ \\
\hline$\left(\mathrm{kg} / \mathrm{m}^{2}\right)$ & Female & 236 & 22.97 & 2.23 & 15 & 28 & \\
\hline Social appearance anxiety & Male & 245 & 34.50 & 10.57 & 16 & 72 & 0.89 \\
\hline scale score & Female & 236 & 33.83 & 11.61 & 17 & 80 & \\
\hline
\end{tabular}

$* \mathrm{p}<0,05$ and $\mathrm{p}<0,001$

When Table 1 is reviewed, it can be seen that average age of the students who participated in the study was 22.43 years for male students, while it was 22.19 years for female students. Average body mass index was found as $24.64 \mathrm{~kg} / \mathrm{m} 2 \mathrm{in}$ male students and as $22.97 \mathrm{~kg} / \mathrm{m} 2$ in female students. Significant differences were found in weight, height and body mass index values of both genders ( $<<0,05$ and $\mathrm{p}<0,001)$. While a body mass index between 20 and 25 is considered as normal, ideal values are 22 for men and 21 for women; however, it will be more appropriate to accept +1 higher values for athletes (Çinar et al., 2004). Social appearance anxiety scale score was found as 33.83 in women and as 34.50 in men. No significant difference was found in social anxiety scale scores in terms of gender ( $p>0,05)$. 
Table 2. Comparison of social appearance anxiety scale scores in terms of field of education

\begin{tabular}{lcccccr}
\hline & $\mathrm{N}$ & Average & St.deviation & Min. & Max. & \multicolumn{1}{c}{ F/LSD } \\
\hline $\begin{array}{l}\text { Sport Education (1) } \\
\text { Art and music }\end{array}$ & 167 & 31.42 & 8.94 & 16 & 80 & $24.10^{* *}$ \\
$\quad$ education (2) & 155 & 33.42 & 12.07 & 16 & 69 & $2>1$ \\
$\begin{array}{l}\text { Educational } \\
\text { Sciences (3) }\end{array}$ & 159 & 37.47 & 11.39 & 21 & 72 & $3>1,2$ \\
Total & 481 & 34.16 & 11.18 & 16 & 80 & \\
$* * \mathrm{p}<0,001$ & & & & & &
\end{tabular}

When Table 2 is reviewed, it can be seen that average social appearance anxiety scale score was 31.42 for sport education students, 33.42 for art and music education students and 37.47 for educational sciences students ( $<<0,001)$.

Table 3. Comparison of social appearance anxiety scale scores in terms of year of study

\begin{tabular}{lcccccc}
\hline & $\mathrm{N}$ & Average & St.deviation & Min. & Max. & F/LSD \\
1st year & 135 & 43.44 & 11.28 & 22 & 72 & $16.18^{* *}$ \\
2nd year & 122 & 35.45 & 11.08 & 20 & 63 & $1>2,3,4$ \\
3rd year & 113 & 35.44 & 10.42 & 19 & 69 & \\
4th year & 111 & 32.77 & 10.04 & 16 & 80 & \\
\hline
\end{tabular}

$* * \mathrm{p}<0,001$

When Table 3 is reviewed, it can be seen that social appearance anxiety scale score was 43.44 for students in their first year of study, 35.45 for students in their second year of study, 35.44 for students in their third year of study, and as 32.77 for students in their fourth year of study $(\mathrm{p}<0,001)$.

Table 4. Comparison of social appearance anxiety scale scores in terms of present weight and height states

\begin{tabular}{clcccc}
\hline \multirow{3}{*}{ Weight } & & $\mathrm{N}$ & Average & St.deviation & F/LSD \\
& Pleased (1) & 182 & 32.38 & 10.82 & $14.18^{* *}$ \\
& Indecisive (2) & 91 & 34.60 & 11.02 & $1<3$ \\
\multirow{3}{*}{ Height } & Not pleased (3) & 208 & 36.83 & 11.10 & \\
& Pleased (1) & 198 & 32.85 & 10.81 & $11.23^{* *}$ \\
& Indecisive (2) & 179 & 37.77 & 10.60 & $1<2,3$ \\
& Not pleased (3) & 104 & 36.37 & 10.05 & \\
& & & & &
\end{tabular}

The scale scores of the students who were pleased with their current weight was 32.38 , while the scale scores of the students who were not pleased was 36.83 and the scale scores of the students who were indecisive was 34.60 ; scale scores of the students who were pleased with their current height was 32.85 , while the scale scores of the students who were indecisive was 37.77 and the scale scores of the students who were not pleased was $36.37(\mathrm{p}<0,001)$.

\section{Discussion}

In the present study, average ages of the students were similar, their weights and heights were higher in favour of male students, as expected. Body mass indices of the students were found to be within normal levels (Table 1). It can be said that in general the results were not worrying for students in terms of weight. In the present study, students who were doing sport and students of the faculty of sport sciences can have increased body mass index values.

In their study, Soylu et al. (2017) found statistically significant difference between groups in terms of the variable of gender in social appearance anxiety scales of adolescent participants. Male students were found to have higher social appearance anxiety when compared with female students. In a study by Çepikkurt and Çoşkun (2010), it was concluded that women were less pleased with their physical appearance and thus they had more negative feelings about their physical appearance when compared with men. In their study, Birchwood et al. (2006) and Dilbaz (1997) found that social anxiety was more frequent in men when compared with women. Alemdağ and Öncü (2015) found statistically significant difference between social appearance anxiety scores and gender. Villiers (2009) concluded that men had less social anxiety than women. Doğan (2009) found that men had higher social anxiety than women. In their studies, 
Fayhout et al. (2005) and Gümüş (2002) reported that social anxiety did not differ in terms of gender. Ümmet (2007) found that social anxiety scores of prospective teachers did not differ in terms of gender variable. Literature review and studies conducted show contradictory information. In a study conducted by Smits et al. (2006), higher social anxiety was reported in women when compared with men. There are also studies in our country which show that women experience more social anxiety than men. In addition to studies which show that social anxiety is more frequent in women when compared with men, there are also studies which show that it is more frequent in men (Alemdağ and Öncü,2015). İmamoğlu et al. (2018) did not find a significant difference between social appearance anxieties of university students in terms of gender. In the present study no significant difference was found in social anxiety scale scores in terms of gender (Table-1). It has been thought that the reason why no significant difference was found in the present study between social appearance anxiety in terms of gender can be because students who participated in the study have similar social activities, social environment and they are exposed to common impacts of the same city since they are studying at the same university.

Tekeli (2017) found that social appearance anxiety of physical education and sport department students were higher when compared with students in other education departments. The reason for this can be the fact that physical education and sport teaching department students care more about their physical appearance. In a study conducted by Yildirım et al. (2011), no significant differences were found in social anxiety levels of prospective teachers studying in different departments. In a study conducted on teachers by Kıliçaslan (2006), physical self perceptions of physical education teachers were found to be $81 \%$ more positive when compared with teachers of other branches. Tekeli (2017) found that physical education and sport department students had statistically significantly higher social appearance anxiety when compared with educational sciences students. In a study they conducted, İmamoğlu et al. (2018) found that students of sport sciences faculty had the lowest social anxiety scores, while students of fine arts faculty had higher social anxiety scores and the students of education faculty had the highest social anxiety scores. Alemdağ and Öncü (2015) found that prospective teachers of physical education and sport had lower social appearance anxiety when compared with students of other departments.

In the present study, statistically significant difference was found between social appearance anxiety scale scores in terms of the field of study (Table 2). The lowest social appearance anxiety scale scores were found in students receiving sport education, while social appearance anxiety scale scores were higher in students receiving art and music education and the highest in students of educational sciences field. The reason why students receiving sport education had lower social anxiety levels when compared with other students can be the fact that they go to different places and take part in different social environments at different times for competitions they participate in and communicate with athletes and people from different cultures and they experience the feeling of self-confidence that sport gives to people (İmamoğlu et al.,2018). Art can also have similar effects. According to Heise (2004), "the intersection of art education with visual culture can create learning experiences preparing students to take part in a democratic society". Participation in exercise has been found to have positive influence on social physical anxiety (Marquez and McAuley, 2001; Edwards et al., 2005). Yüceant (2013) found that prospective teachers of physical education had low averages of social anxiety level. In one study, Tekeli (2017) found that the participants had a less than moderate level of social appearance anxiety with an average score of 32.98. Similar results in literature also show that prospective teachers studying in different departments have less than moderate level of social appearance anxiety (Alemdağ, 2013). Sportive activities have positive influence on posture (Yamak et al.,2018) and this can have an influence on social appearance anxiety. In the present study, it can be said that students receiving sport education have less than moderate level of social appearance anxiety.

In their study, Telli and Ünal (2016) found that social appearance anxiety of students who participated in the study was found to differ according to age, department and year of study. İmamoğlu et al. (2018) found a significant difference between social appearance anxieties of students in terms of their year of study. Tekeli (2017) found the highest level of social appearance anxiety in physical education students in their first year. In their study, Alemdağ and Öncü (2015) found that average social appearance anxiety scores of physical education teaching first and second year students were higher than those of third and fourth year students. This result shows that first and second year students had higher social appearance anxiety than third and fourth year students. In other words, we can say that as the year of study increase, social appearance anxiety decreased. In Baltac1 (2010)'s study, prospective teachers in their second year of study had higher social appearance anxiety scale scores than students in their third and fourth year of study. Yildirım et al. (2011) found that social anxiety scale scores of students in their first year of study were significantly higher when compared with students in their fourth year of study. Witchen and Fehm (2003) found that students in their first years of study had higher social anxiety levels when compared with students in more advanced levels of study. In the present study, statistically significant difference was found between students' years of study. This difference was found to result from the high social appearance anxiety levels of students in their first year of study. It is thought that adaptation problems of students in their first year can have caused social appearance anxiety. 
Tekeli (2017) found that the highest social appearance anxiety was found in low weight participants studying in physical education departments, while the highest social appearance anxiety was found in low weight participants studying at education faculty departments. In the present study, the students who were pleased with their weight and height had lower social appearance anxiety sores than the students who were not. Social appearance anxiety can be decreased by getting psychological help about weight and making use of weight loss methods. Koca et al. (2018) found that high school students who were doing team sports had more positive characteristics than those who were doing individual sport and those who were not doing any sport at all. They recommended sport to students who were not doing sport and students who were doing individual sports to do team sports. In their study, İslam and İmamoğlu (2019) stated that prospective teachers of physical education could have increased attitudes towards teaching profession due to the socializing, responsibility, belonging and associating characteristics of sport. They recommended educational activities such as formation classes, courses and seminars. The same recommendations can be made to decrease social appearance anxiety.

As a conclusion, it was found that social appearance anxiety differed in terms of the students' field of study. Social appearance anxiety levels of students receiving sport education were found to be lower than those of students receiving education in the fields of art, music and educational sciences. In terms of contributions to social appearance, art and music education are also thought to cause similar influence on sport. Giving sport education to students who are not receiving sport education or making them do sport and giving those interested in sport a chance to be interested in art can be a factor in decreasing social appearance anxiety.

\section{References}

Alemda $\breve{g}$, S. (2013). Analysis of the association between participation in physical activity, social appearance anxiety and social self-efficacy. Doctoral Thesis. Karadeniz Technical University, Institute of Educational Sciences. Trabzon.

Alemdağ, S., \& Öncü, E. (2015). Analysis of participation in physical activity and social appearance anxiety in prospective teachers. International Journal of Science Culture and Sport (IntJSCS), Special Issue 3, 287-300. https://doi.org/10.14486/IJSCS291

Çepikkurt, F., \& Çoşkun, F. (2010). University student dancers' levels of social physical anxiety and being pleased with their bodily image. Pamukkale Journal of Sport Sciences, 1(2), 17-24.

Çınar, V., Bostancı, Ö., İmamoğlu, O., Kabadayı, M., \& Şahan, H. (2004). Anthropometric Differences in the Athletes who Are Students in Accordance with the Branch and Sexuality, Journal of Physical Education and Sport Sciences, 6(2), 26-34. https://doi.org/10.1016/j.compedu.2014.09.007

Demirer, Y. (2005). Bodily perception and mental health. http://www.acilservis.pro/beden-algisi-ve-ruh-sagligi

Dilbaz, N. (1997). Social phobia. Journal of Psychiatry World, 1, 18-24.

Dindar, M., \& Akbulut, Y. (2015). Role of self-efficacy and social appearance anxiety on gaming motivations of MMOFPS players, Computers and Education, 81, 26-34.

Doğan, T. (2009). Analysis of cognitive and self-assessment processes in terms of social anxiety. Doctoral Thesis. Sakarya University, Institute of Social Sciences, Sakarya.

Edwards, S. D., Ngcobo, H. S., Edwards, D. J., \& Palavar, K. (2005). Exploring the relationship between physical activity, psychological well-being and physical self-perception in different exercise groups. South African Journal for Research in Sport, Physical Education and Recreation, 27(1), 59-74.

Eren, G. A. (2002). The effects of social anxiety coping program on university students' social anxiety levels. Doctoral Thesis. Ankara University, Institute of Educational Sciences.

Ergür, E. (1996). The association between body-self perception and mental health in university students. Postgraduate thesis. Ege University. Institute of Social Sciences, İzmir.

Hart, T. A., Flora, D. B., Palyo, S. A., Fresco, D. M., Holle, C., \& Heimberg, R. C. (2008). Development and Examination of the Social Appearance Anxiety Scale. Assessment, 15, 48-59. https://doi.org/10.1177/1073191107306673

Heise, D. (2004). Is Visual Culture Becoming Our Canon of Art? Art Education. 57(5), 41-46 (September). https://doi.org/10.1080/00043125.2004.11653567

İmamoğlu, G., Satıcı, A., Ermiş, E., \& Ermiş, A. (2018). Social Appearance Anxiety in Students of the Faculties of Sport Sciences, Fine Arts and Education, $6^{\text {th }}$ International Conference on Science Culture and Sport, Proceedings Book, Ankara: 525-534, www.iscs -a.org. 
İslam, A., \& İmamoğlu, O. (2019). The Examination of Attitudes Relating to Teaching Professions of University Students Receiving Sport Education (Sample of Ordu University), MANAS Journal of Social Studies, 8(1), 1349-1361.

Kılıç, M. (2015). Analysis of the association between university students' social appearance anxiety, self-respect and loneliness levels. Postgraduate thesis. Selçuk University. Institute of Health Sciences, Konya.

Kılıçarslan, E. (2006). Comparison of Physical sense of self in teachers of physical education and other branches: (Kdz. Ereğli sample). Postgraduate thesis. Sakarya University. Institute of Social Sciences, Sakarya.

Koca, F., İmamoğlu, G., \& İmamoğlu, O. (2018). Sports Status of High School Students and Investigation of Personality Characteristics by Gender, The Journal of Academic Social Science, 6(80), 31-42.

Marquez, D. X., \& McAuley, E., (2001).Physique anxiety and self-efficacy influences on perceptions of physical evaluation. Social Behavior and Personality: an international journal, 29(7), 649-659. https://doi.org/10.2224/sbp.2001.29.7.649

Mülazımoğlu, B., Erturan, İ. Ö. G., \& Arslan, Y. (2014). Achievement Goals in Turkish High School PE Setting: The Predicting Role of Social Physique Anxiety. International Journal of Educational Research, 67, 30-39. https://doi.org/10.1016/j.ijer.2014.04.004

Smits, A. J., Powers, B. M., Buxkamper, R., \&Telch, M. J. (2006). The efficacy of video type feedback for enhancing the effects of exposure-based treatment for social anxiety disorder: a controlled investigation. Behaviour Research and Therapy, 44, 1773-1785. https://doi.org/10.1016/j.brat.2006.01.001

Soylu, Y., Atik, F., \& Öçalan, M., (2017). Analysis of social appearance anxiety levels of adolescents, Journal of Sport and educational sciences, SI(1), 38-45

Tekeli, Ş. C. (2017). Comparison of social appearance anxiety and academic self-efficacy levels of prospective physical education and sport teachers and other prospective teachers. Postgraduate thesis. Bartın University, Institute of Educational Sciences, Bartın.

Telli, E., \& Ünal, Z. (2016). Social appearance anxiety of university students in terms of their socio-demographic characteristics: A field study. Mehmet Akif University, Institute of Social Sciences Journal, 8(15), 134-146.

Ümmet, D. (2007). Analysis of social anxiety in university students within the context of gender roles and family environment. Post graduate thesis. Marmara University, Institute of Educational Sciences, İstanbul.

Villiers, D. P. (2009). Perfectionism and social anxiety among college students. Counselling Psychology Dissertations, 4.

Yamak, B., İmamoğlu, O., \& Çebi, M. (2016). The Effects of the Physical Fitness Levels of Adolescents on Body Image, Self-Concept and Stress Levels, The Journal of Academic Social Science, 4(34), 191-201. https://doi.org/10.16992/ASOS.6542

Yamak, B., İmamoğlu, O., İslamoğlu, İ., \& Çebi, M. (2018). The Effects of Exercise on Body Posture, Turkish Studies Social Sciences, 13(18), 1377-1388.

Yıldıran, İ., \& Yetim, A. A., (1996). A study on primary objectives of physical education and sport lesson in secondary education. Gazi University, Journal of physical education and sport sciences, 1(3), 1996.

Yıldırım, T., Çırak, Y., \& Konan, N. (2011). Social anxiety in prospective teachers. Inönü University Journal of Education Faculty, 12(1), 85-100.

Yüceant, M. (2013). Analysis of prospective physical education teachers' social appearance anxiety levels in terms of different variables. Post graduate thesis. Aksaray University, Institute of Social Sciences, Aksaray.

\section{Copyrights}

Copyright for this article is retained by the author(s), with first publication rights granted to the journal.

This is an open-access article distributed under the terms and conditions of the Creative Commons Attribution license which permits unrestricted use, distribution, and reproduction in any medium, provided the original work is properly cited. 